\title{
High-performance Liquid Chromatography-Fluorescence
}

National Cancer Institute

\section{Source}

National Cancer Institute. High-performance Liquid Chromatography-Fluorescence. NCI Thesaurus. Code C120692.

An analytical technique where high performance liquid chromatography with a

fluorescence detector is used to separate, identify, and quantify substances in a sample. 